\title{
New forms for our new sensations: a convergência de novos sons e imagens na modernidade e o seu reflexo na literatura de Virginia Woolf
}

\section{New forms for our new sensations: the convergence of new sounds and images in modernity and its reflection in Virginia Woolf's literature}

\author{
Isadora Meneses Rodrigues \\ Universidade Federal do Ceará, Fortaleza, Brasil \\ isadorarodrigues12@gmail.com
}

\begin{abstract}
Resumo: "New forms for our new sensations", foi o que declarou a escritora inglesa Virginia Woolf em um de seus primeiros ensaios, Hours in a Library, escrito para jornal Times Literary Supplement, em 1916. Nesse texto, a autora discorre sobre a necessidade de a literatura criar novas formas e técnicas para expressar as experiências audiovisuais singulares que contaminaram as cidades na primeira metade do século XX. Nesse sentido, este trabalho tem como objetivo refletir sobre como essas alterações na matéria do pensamento e da experiência acabaram reverberando na ficção de fluxo de consciência, mais especificamente na literatura woolfiana. Para evidenciar essa relação, nos apoiamos em teóricos que tratam da transformação na estrutura da experiência do homem como sendo um reflexo das mudanças no cotidiano provocadas pela modernidade, como Walter Benjamin, George Simmel e Marshall Berman.
\end{abstract}

Palavras- chaves: Virginia Woolf; Fluxo de consciência; Modernidade; Percepção.

\begin{abstract}
New forms for our new sensations', this sentence was written by the English writer Virginia Woolf in one of her first essays, Hours in a Library, published in the newspapaer Times Literary supplement in 1916. In this text, the author discusses the need for literature to create new forms and techniques to express the unique audiovisual experience that contaminated cities in the first half of the twentieth century. In this sense, this research aims to reflect on how these changes in the field of thought and experience ended up reverberating in the stream of consciousness fiction, more specifically in Woolf's literature. To evince this relationship, we rely on theorists that think about the transformation of the structure of man's experience as a reflection of the changes in daily life caused by modernity, such as Walter Benjamin, Georg Simmel and Marshall Berman
\end{abstract}

Keywords: Virginia Woolf; Stream of Consciousness; Modernity; Perception

O mundo erguera seu chicote; onde iria ele se abater? Tudo tinha parado. A trepidação dos motores soava como uma pulsação martelando irregularmente ao longo de todo um corpo. O sol se tornou extraordinariamente forte porque o carro parara defronte à vitrine de Mulberry; velhas senhoras no andar de cima dos ônibus estenderam suas sombrinhas pretas; como um estalido, uma sombrinha verde abriuse aqui, outra, vermelha, ali adiante. A Sra. Dalloway, chegando até a janela com os braços carregados de ervilhas-de-cheiro, olhou para fora, o pequeno e rosado rosto marcado pela curiosidade. Todos observavam o carro. Septimus observava. Rapazes

eISSN: 2179-8478

DOI: $10.17851 / 2179-8478.8 .02-16$ 
saltavam das bicicletas. O tráfego tornava-se mais pesado. E o carro ficou ali parado, com as cortinas baixadas, e elas tinham um estampado curioso, como uma árvore, pensou Septimus, e essa gradual convergência de tudo, diante de seus olhos, para um único centro, como se algum horror houvesse chegado quase à superfície e estivesse prestes a irromper em chamas, deixou-o aterrorizado. $\mathrm{O}$ mundo tremia e oscilava e ameaçava irromper em chamas. Sou eu quem está impedindo o trânsito, pensou. Não era ele que estava sendo observado, não era ele que estava sendo apontado; não estava ele colado ali, grudado à calçada, por algum desígnio? Mas qual? ${ }^{1}$ (WOOLF, 2012, p. 16 e 17). ${ }^{2}$

A cidade pulsa no corpo da Sra. Dalloway e Septimus. Mas não é qualquer cidade que agita e inquieta os protagonistas do romance mais famoso da escritora Virginia Woolf, a cidade que pulsa é moderna. A trepidação dos motores dos carros de passeio e dos ônibus, as vitrines, a quantidade de gente que anda nas ruas. É essa Londres do começo do século XX, em que há a convergência de tudo, que afeta Clarissa e Septimus, causando uma palpitação, como descreve Woolf, que parece martelar irregularmente por todo o corpo.

O episódio da citação acima faz parte de Mrs. Dalloway, considerado o primeiro romance de fluxo de consciência da escritora. Segundo o teórico Robert Humphrey, as narrativas de fluxo de consciência caracterizam-se como um tipo de ficção em que "a ênfase principal é posta na exploração dos níveis de consciência que antecedem a fala com a finalidade de revelar, antes de mais nada, o estado psíquico dos personagens" (HUMPHREY, 1976, p.4). Ou seja, é um método literário de representação da vida interior que dá ao leitor a sensação de que não existe um narrador intermediando o que se passa na mente dos personagens.

\footnotetext{
1 "The world has raised its whip; where will it descend? Everything had come to a standstill. The throb of the motor engines sounded like a pulse irregularly drumming through the entire body. The sun became extraordinarily hot because the motor car had stopped outside Mullberry's shop window; old ladies on the tops of omnibuses spread their black parasols; here a green, here a red parasol opened with a little pop. Mrs. Dalloway, coming to the window with her arms full of sweet peas, looked out with her little pink face pursed in inquiry. Everyone looked at the motor car. Septimus looked. Boys on bicycles sprang off. Traffic accumulated. And there the motor car stood, with drawn blinds, and upon them a curious pattern like a tree, Septimus thought, and this gradual drawing together of everything to one centre before his eyes, as if some horror had come almost to the surface and was about to burst into flames, terrified him. The world wavered and quivered and threatened to burst into flames. It is I who am blocking the way, he thought. Was he not being looked at and pointed at; was he not weighted there, rooted to the pavement, for a purpose? But for what purpose?"

${ }^{2}$ Em relação à edição do trabalho, indicamos que todas as traduções de citações em língua estrangeira são de nossa autoria, com exceção das passagens de Mrs. Dalloway, que são de Tomaz Tadeu (2012). Para fazer ecoar a voz da escritora, optamos por colocar a citação dos textos literários no original em nota de rodapé.
} 
Woolf declarou, no ensaio Modern Fiction, escrito em 1919, que a busca pela compreensão da realidade por meio da literatura não é uma questão de descrição dos aspectos materiais e exteriores da vida. Para retratar a realidade na ficção, afirmava a autora, é preciso "registrar os átomos que caem sobre a mente, na ordem que eles caem." (WOOLF, 1919, n.p.). O "material adequado da ficção" seria, então, o exame de "uma mente comum em um dia comum.”(WOOLF, 1919, n.p.).

Modern Fiction, que a autora escreve com intenção de analisar alguns romances de James Joyce, soa também como uma defesa da sua própria obra. Isso porque, alguns anos depois, em 1925, Woolf publicaria justamente Mrs. Dalloway, romance que narra um dia na vida de uma mulher comum, a dona de casa Clarissa Dalloway, que sai para comprar flores para uma festa que acontecerá em sua casa durante a noite. O outro personagem central da trama é o jovem Septimus Warren Smith. Vivendo as consequências de um trauma de guerra, Septimus está indo com a esposa, Rezia, para uma consulta psiquiátrica. Ambos, Clarissa e Septimus, são mostrados em uma mesmo dia de junho de 1923, na cidade de Londres. Em dado momento da narrativa, a vida desses dois personagens se cruza, quando o doutor Bradshaw, pertencente à alta sociedade londrina, comunica o suicídio de Septimus à Clarissa, durante a festa em sua casa. Mesmo sem nunca chegarem a se conhecer, as narrativas da vida de Clarissa e Septimus se atravessam constantemente- ou por conhecerem as mesmas pessoas, como o doutor Bradshaw, ou por presenciarem os mesmos episódios, durante esse dia, em Londres. Nas mais de 200 páginas do romance, acompanhamos o mundo exterior praticamente pela descrição da mente de Clarissa, de Septimus e dos outros personagens que os cercam. É por meio do fluxo dos seus pensamentos que conhecemos suas histórias e o modo como eles percebem a realidade de suas vidas e da cidade.

Com o do fluxo de consciência, há, no romance, uma fragmentação da noção do espaço e do tempo da narrativa. Apesar de a história se passar em apenas um dia, entre as 10 horas da manhã e a meia noite, o material psicológico exposto percorre mais de 18 anos da vida de Clarissa. Os locais apresentados ao leitor também são diversos: Londres, um campo de batalha em Paris, uma casa de praia em Burton e a Itália. O leitor segue o rumo da mente dos personagens.

De acordo com Monique Nathan (1984), biógrafa de Woolf, os textos da escritora 
revelam as marcas profundas do seu tempo. Um tempo em que o interesse pela consciência e pelo processo de apreensão do mundo era partilhado não só pelas artes, mas também pela ciência. Basta lembrar que, em 1899, por exemplo, Freud lançou o seu mais famoso livro, $A$ Interpretação dos Sonhos, formulando uma teoria do estudo da mente e da conduta humana. Alguns anos antes, em 1880, o filósofo Friedrich Nietzsche manifestava esperança de que a psicologia tornar-se-ia a principal disciplina das ciências. Segundo o historiador Peter Gay (2009, p.188), os romancistas modernos, como se tivessem ouvido Nietzsche, transformaram a literatura do século XX numa "profunda exploração psicológica".

De acordo Gay (2009, p.169), desde meados do século XVII, a literatura já reivindicava a vida mental como um domínio que lhe pertencia. O realismo, por exemplo, movimento literário dominante até o final do século XIX, desenvolveu diversos artifícios para apresentação do pensamento na literatura. Gustave Flaubert, com o personagem Frédéric de $A$ educação sentimental (1870), inaugurou a figura do flâneur- o personagem ocioso, que vagueia pela cidade, vê e, principalmente, reflete. Além de Flaubert, escritores como Fiodor Dostoievski e Henry James, também no século XIX, produziram textos com longas passagens introspectivas. Édouard Dujardin, com Os Loureiros Estão Cortados, de 1887, é considerado o precursor do uso do monólogo interior indireto ${ }^{3}$, técnica que viria a ser uma das mais utilizadas por Virginia Woolf para a apresentação do fluxo de consciência.

Contudo, foi apenas na primeira metade do século XX que a literatura passou a ter como tema principal a expressão dos devaneios da mente humana. A originalidade do romance modernista, assim, reside não tanto na descoberta do território mental, mas no remapeamento desse território. Suas técnicas se destinavam a cavar cada vez mais fundo muito mais fundo - do que jamais fizera qualquer romancista preso à tradição (GAY, 2009, p.189).

Essa busca pela descrição absoluta do presente no momento mesmo em que ele é sentido pela mente - o tempo mais evidente e palpável, mas que sempre nos escapa completamente - foi impulsionada pelas transformações pelas quais passavam as metrópoles modernas no período em que Woolf produziu a sua obra. Essa mudança na matéria do

\footnotetext{
${ }^{3} \mathrm{O}$ monólogo indireto ocorre quando há alguma interferência do narrador nas divagações do personagem. É o autor onisciente que apresenta o material não falado, a consciência. Ver mais em Humphrey (1976, p. 21-30)
} 
pensamento e da experiência acabou reverberando por toda a arte do século XX e os escritores que ficaram famosos pelo uso do fluxo de consciência discutiram na arte algo que estava se consolidando no campo social. No mundo moderno há uma forte mudança no campo em que a percepção ocorre devido, principalmente, a uma enorme convergência de novos sons e imagens, livros como Ulisses (1922), de James Joyce, e Mrs. Dalloway tocam indiretamente nessas transformações.

Nesse sentido, o que nos interessa discutir neste trabalho é o quanto a consolidação das cidades modernas, com as suas singularidades audiovisuais, afetaram o modo como os homens se colocam no mundo e percebem a realidade e como essas novas formas de percepção são refletidas na literatura de fluxo de consciência do começo do século XX, em especial da escritora inglesa Virginia Woolf. A romancista, ensaísta e contista transformou Londres, com os seus estímulos à vista e ao ouvido, em uma protagonista ativa de Mrs. Dalloway. De acordo com a crítica Anne Banfield (2009, p. 883), o romance é para Woolf "a exploração da força metonímica da vida urbana" e é com a ajuda de alguns pensadores da modernidade, como Walter Benjamin e Georg Simmel, que iremos refletir sobre a representação dessa sobrecarga sensorial que leva ao limite o nosso sistema nervoso.

Mas que transformações são essas e o que estamos chamando de modernidade? Aqui nos apoiamos em Marshall Berman, que refletiu sobre a "aventura" da modernidade em Tudo que é sólido desmancha no ar (1986). Berman divide a modernidade em vários períodos, fazendo um passeio por diversos textos e explorando autores de épocas distintas que trataram do tema, como Karl Marx, Charles Baudelaire, Goethe, entre outros. Para Berman, a modernidade é um paradoxo, uma unidade sem coesão, pois, ao mesmo tempo em que une as pessoas, abalando as fronteiras geográficas, raciais e de classes, as coloca em um ambiente conflitante e contraditório.

Trata-se de uma paisagem de engenhos a vapor, fábricas automatizadas, ferrovias, amplas novas zonas industriais; prolíficas cidades que cresceram do dia para a noite, quase sempre com aterradoras consequências para o ser humano; jornais diários, telégrafos, telefones e outros instrumentos de media, que se comunicam em escala cada vez maior; Estados nacionais cada vez mais fortes e conglomerados multinacionais de capital; movimentos sociais de massa, que lutam contra essas modernizações de cima para baixo, contando só com seus próprios meios de modernização de baixo para cima; um mercado mundial que a tudo abarca, em 
crescente expansão, capaz de um estarrecedor desperdício e devastação, capaz de tudo exceto solidez e estabilidade. (BERMAN, 1986, p.12)

O filósofo Jean-Jacques Rousseau foi o primeiro a usar a palavra moderniste no sentido em que os séculos XIX e XX a usaram. Apesar de ter refletido sobre a primeira fase da modernidade, antes das revoluções francesa e americana, na passagem a seguir, retirada da novela Júlia ou a nova Heloísa, de 1761, Rousseau já aparece com temas que seriam bastante debatidos nos séculos posteriores. Os sentimentos que a experimentação da vida metropolitana causa no homem é o principal deles:

Eu começo a sentir a embriaguez a que essa vida agitada e tumultuosa me condena. Com tal quantidade de objetos desfilando diante de meus olhos, eu vou ficando aturdido. De todas as coisas que me atraem, nenhuma toca o meu coração, embora todas juntas perturbem meus sentimentos, de modo a fazer que eu esqueça o que sou e qual meu lugar. (ROUSSEAU apud BERMAN, 1986, p.12).

Anthony Giddens também trata dessa sensação de agitação e tumulto descrita por Rousseau. Para o autor, essa impressão vem de uma característica fundamental da era moderna, o seu dinamismo. O mundo que surge com a revolução industrial e os novos dispositivos de produção e reprodução de imagens é um "mundo em disparada: em que não só o ritmo da mudança social é muito mais rápido que em qualquer sistema anterior; também a amplitude e a profundidade com que ela afeta práticas sociais e modos de comportamento preexistentes são maiores". (GIDDENS, 2002, p. 22).

O termo modernidade é empregado por Giddens para referir-se às instituições e modos de comportamento estabelecidos pela primeira vez na Europa depois do feudalismo, mas que no século XX se tornaram mundiais em seu impacto. Essas instituições introduziram transformações que se entrelaçam de maneira direta com a vida individual, e, portanto, com o eu. Além disso, são instituições que se estabelecem como modalidades de reorganização do tempo e do espaço, na medida em que constituem novas dinâmicas de percepção para os indivíduos.

Foi o sociólogo alemão Georg Simmel, em suas teorias a respeito da vida social, um dos primeiros a enfatizar os modos pelos quais as mudanças ocorridas nas cidades durante os 
séculos XIX e XX acabaram por transformar também a estrutura da experiência do homem.

As mudanças de que fala Simmel, que afetam diversas dimensões do social, são o acelerado aumento populacional, o surgimento dos carros motorizados, da imprensa, da fotografia e do cinema. Essas transformações, como afirma o autor no ensaio A metrópole e a vida mental (1973), geram uma intensificação dos estímulos nervosos, que resultam num homem que se relaciona com o mundo de forma bem diferente do homem rural, em que "o conjunto sensorial de imagens mentais flui mais lentamente, de modo mais habitual e mais uniforme. " (SIMMEL,1973, p.12). A ideia do fluir, portanto, é fundamental para entender a nova relação entre homem e mundo. O fluxo de informação é gigante e essas diferentes quantidades de estímulos alteram as relações de continuidade e associação existentes no nosso cérebro.

\footnotetext{
[...] a rápida convergência de imagens em mudança, a descontinuidade aguda contida na apreensão com uma única vista de olhos e o inesperado de impressões súbitas. Tais são as condições psicológicas que a metrópole cria com cada atravessar de rua, com o ritmo e a multiplicidade da vida econômica, ocupacional e social, a cidade faz um contraste profundo com a vida de cidade pequena e a vida rural no que se refere aos fundamentos sensórios da vida psíquica. (Ibdem, p.12)
}

Walter Benjamin, que tem nos textos de Simmel uma base importante para suas pesquisas, em dois textos seminais da sua bibliografia trabalha diretamente com a relação entre a modernidade e a vida cotidiana. Em A Obra de Arte na era da sua Reprodutibilidade Técnica (1987), declara que a percepção é condicionada historicamente, ao afirmar que "no interior de grandes períodos históricos, a forma de percepção das coletividades humanas se transforma ao mesmo tempo em que seu modo de existência" (BENJAMIN, 1987, p.169). Benjamin coloca como marco dessa mudança da forma de percepção na modernidade o surgimento da fotografia e do cinema.

No ensaio Sobre alguns temas de Baudelaire (2000), o autor volta a afirmar que a vida moderna provoca uma mudança na estrutura da experiência e essa mudança é em direção ao momentâneo e ao fragmentário. Esse texto de Benjamin é particularmente interessante para refletir sobre a obra de Woolf e sobre o fluxo de consciência de maneira geral. Isso porque o autor vai buscar no filósofo Henri Bergson e no escritor Marcel Proust algumas reflexões 
sobre a forma de aparição da memória e como isso se dá justamente na literatura, chegando a afirmar que "a experiência não consiste precisamente em acontecimentos fixados com exatidão na lembrança, e sim, em dados acumulados, frequentemente de forma inconsciente, que afluem à memoria" (BENJAMIN, 2000, p.38).

Essas ideias de não precisão, acumulação de experiência e memória são fundamentais para a construção do fluxo de consciência. Isso porque um dos problemas básicos de representação do pensamento dentro da limitação de uma ficção compreensível é a falta de encadeamento lógico das ideias que surgem na nossa mente. Para solucionar o problema, Woolf se vale da livre associação psicológica combinada com o monólogo indireto. A importância da livre associação psicológica para a construção do fluxo de consciência se deve, segundo Robert Humphrey, ao fato de que:

\begin{abstract}
A psique, cuja atividade é quase ininterrupta, não pode ser concentrada por muito tempo em seus processos, mesmo quando é fortemente dominada; exercendo-se pouco esforço para concentrá-la, seu foco permanece sobre uma única coisa por uma questão de instantes apenas. Contudo, a atividade da consciência deve ter conteúdo, o qual é fornecido pelo poder que tem uma coisa de sugerir outra, através de uma associação de qualidades em comum ou contrastantes, em todo ou em parte mesmo a mais vaga das sugestões. (HUMPHREY, 1976, p.38)
\end{abstract}

Portanto, a livre associação ocorre quando determinado personagem começa a ligar vários fatos de sua vida, podendo ter ocorrido em tempos e espaços distintos, sem explicar ao leitor se está adiantando ou voltando no tempo. Podemos encontrar uma junção do monólogo interior indireto e do princípio de livre associação logo nas primeiras páginas de Mrs. Dalloway, quando a personagem Clarissa sai para comprar flores. Em apenas poucas horas, enquanto caminha pelas ruas de Londres, temos um panorama de múltiplas situações vividas por ela ao longo de vários anos de sua vida. Diversos personagens são apresentados ao leitor: o ex-namorado Peter Walsh, o marido Richard, sua filha Elisabeth e alguns amigos. A seguir, um pequeno fragmento das primeiras linhas do romance, um monólogo indireto que dura cerca de quinze páginas:

A Sra. Dalloway disse que ela própria iria comprar as flores. Quanto a Lucy, já estava com o serviço determinado. As portas seriam retiradas dos gonzos; em pouco chegaria o pessoal de Rumpelmayer. Mas que manhã, pensou Clarissa Dalloway fresca como para crianças numa praia. Que frêmito! Que mergulho! Pois sempre 
assim lhe parecera quando, com um leve ringir de gonzos, que ainda agora ouvia, abria de súbito as vidraças e mergulhava ao ar livre, lá em Bourton. Que fresco, que calmo, mais que o de hoje, não era então o ar da manhãzinha; como o tapa de uma onda; como o beijo de uma onda; frio, fino, e ainda (para a menina de dezoito anos que ela era em Bourton) solene, sentindo, como sentia, parada ali ante a janela aberta, que alguma coisa terrível ia acontecer; olhando para as flores, para os troncos, de onde desprendia a névoa, para as gralhas, que se alçavam e abatiam; parada e olhando até que Peter Walsh lhe dizia: 'Meditando entre os legumes? (WOOLF, 2012, p. 5). ${ }^{4}$

Podemos notar, pela passagem, que a escrita em fluxo de consciência dá uma atenção especial ao que James Wood (2001) chama de detalhe literário. A presença dos "gonzos", por exemplo, é uma descrição que não está ligada à composição do personagem. São detalhes do ambiente que ronda Clarissa, que captam sua atenção e que a levam a pensar no passado, em outro ringir de gonzos, anos antes, em Bourton. James Wood descreve o compromisso dos escritores modernos com o detalhe como sendo algo da ordem da qualidade cinematográfica, que tenta captar a essência do funcionamento da mente.

$\mathrm{O}$ artifício consiste na escolha do detalhe. Na vida, podemos desviar os olhos e a cabeça, mas na verdade somos como câmeras impotentes. A lente é de grande abertura e captamos tudo o que aparece. A memória seleciona, mas não do jeito que a narrativa literária seleciona. Nossas lembranças possuem talento estético (WOOD, 2011, p.57).

A força da experiência na ativação dos processos mentais é um dos aspectos fundamentais na literatura de Virginia Woolf, são sempre os fatos exteriores à mente que disparam o fluxo de consciência. É a experimentação da cidade que ativa a memória. Ao invés de comunicar essa experiência, os personagens pensam. Em Experiência e Pobreza, escrito em 1933, Benjamin afirma que os combatentes da primeira guerra mundial voltaram

\footnotetext{
4 "Mrs. Dalloway said she would buy the flowers herself. For Lucy had her work cut out for her. The doors would be taken off their hinges; Rumpelmayer's men were coming. And then, thought Clarissa Dalloway, what a morning - fresh as if issued to children on a beach. What a lark! What a plunge! For so it had always seemed to her when, with a little squeak of the hinges, which she could hear now, she had burst open the French windows and plunged at Bourton into the open air. How fresh, how calm, stiller than this of course, the air was in the early morning; like the flap of a wave; the kiss of a wave; chill and sharp and yet (for a girl of eighteen as she then was) solemn, feeling as she did, standing there at the open window, that something awful was about to happen; looking at the flowers, at the trees with the smoke winding of them and rooks rising, falling; standing and looking until Peter Walsh said, 'Musing among vegetables?'” .
} 
do campo de batalha silenciosos e mais pobres em experiências comunicáveis. Em $O$ Narrador (1987), para fazer uma reflexão sobre o desaparecimento das narrações na história da civilização, Benjamin reflete sobre a nossa incapacidade de intercambiar experiências como sendo um reflexo da modernidade. A virada do século XIX para o XX foi um choque, o intenso crescimento das cidades e o crescente fluxo de informações tiraram do homem a capacidade de ter experiências reais. $\mathrm{O}$ autor chama atenção para a geração que viu o velho e o novo, que viveu as transformações que alterariam de modo vigoroso os modos de experimentação da realidade.

Uma geração que ainda fora à escola num bonde puxado por cavalos se encontrou ao ar livre numa paisagem em que nada parecia inalterado, exceto as nuvens, e debaixo dela, num campo de forças de torrentes e explosões, o frágil e minúsculo corpo humano. (BENJAMIN, 1987, p. 1987).

Virginia Woolf e seus personagens fazem parte dessa geração de que fala Benjamin, que transitou pelo fim do século XIX e viu a consolidação de todas as criações e inovações da primeira metade do século XX. A geração que viveu todas as consequências da modernidade. Septimus, tendo vivido os horrores da Primeira Guerra Mundial, inclusive perdendo um amigo em batalha, Evans, parece incapaz de compartilhar seus sentimentos com aqueles que ficaram a sua espera, como a esposa, Rezia. O ex-soldado vive alheio ao mundo em sua volta e parece não ter mais a capacidade de ser afetado pelo cotidiano, sempre relacionando os acontecimentos banais que o cercam com a sua experiência nos campos de batalha. $\mathrm{Na}$ passagem seguinte, temos um desses momentos de descrição dos efeitos causados pela guerra na vida do personagem:

Eles tinham que estar sempre juntos, compartilhar, brigar, discutir. Mas quando Evans (Rezia, que o tinha visto uma vez, referia-se a ele como "um homem calado", um homem entroncado, ruivo, retraído na companhia de mulheres), quando Evans foi morto, bem pouco antes do Armistício, na Itália, Septimus, além de não demonstrar qualquer emoção ou de não reconhecer que aqui terminava uma amizade, congratulou-se por reagir tão contida e racionalmente. A Guerra tinha lhe dado uma lição. Foi sublime. Tinha passado pela experiência toda, amizade, Guerra Europeia, morte, tivera uma promoção, ainda não tinha trinta anos e estava destinado a sobreviver. Esteve bem no centro de tudo. As últimas granadas por pouco não o atingiram. Foi com indiferença que as viu explodirem. Quando veio a vez paz, estava em Milão, aquartelado numa pousada, com um pátio interno, flores em banheiras, pequenas mesas ao ar livre, as filhas do dono confeccionando 
chapéus, e com Lucrezia, a mais nova das duas, firmou compromisso de casamento, numa noite em que foi tomado de pânico - por não conseguir sentir nada (WOOLF, 2012, p.96) ${ }^{5}$

Não ser afetado pelo mundo. Em diversas passagens, por meio de monólogos, Woolf descreve Septimus pensando que não consegue mais sentir o mundo. Essas considerações parecem, num primeiro momento, distanciar o personagem de Clarissa Dalloway, sensível a cada detalhe que passa diante dos seus olhos. Woolf está sempre descrevendo o fascínio de Clarissa pela Londres moderna:

"Bond Street a fascinava; a Bond Street de manhã cedo na alta estação; suas flâmulas flutuando; suas lojas; sem alarde; suas lantejoulas; uma peça de tweed na loja em que seu pai comprara seus termos durante cinquenta anos; umas poucas pérolas; salmão num bloco de gelo." (WOOLF, 2012, p.13).

Contudo, Septimus parece ser um visionário, tendo um olhar mais pessimista sobre essa modernidade que experimenta. Em determinado momento do romance, ele parece constatar que o fato de ele não conseguir sentir é culpa da própria cidade, que o devora.

Belíssimo!, murmurava ela, cutucando Septimus, para que ele visse. Mas a beleza ficava do lado de trás de um espelho. Nem mesmo o paladar (Rezia adorava sorvete, chocolate, doces) lhe dava qualquer prazer. Ele colocava a sua xícara na mesinha de mármore. Observava as pessoas lá fora; pareciam felizes, juntando-se no meio da rua, gritando, rindo, brigando por nada. Mas ele não tinha paladar, não conseguia sentir. (...). É bem possível, pensava Septimus, contemplando a Inglaterra da janela

\footnotetext{
5 "They had to be together, share with each other, fight with each other, quarrel with each other. But when Evans (Rezia, who had only seen him once, called him 'a quiet man', a sturdy red-haired man, undemonstrative in the company of women), when Evans was killed, just before the Armistice, in Italy, Septimus, far from showing any emotion or recognizing the here was the end of a friendship, congratulated himself upon feeling very little and very reasonably. The War had taught him. It was sublime. He had gone through the whole show, friendship, European War, death, won promotion, was still under thirty and was bound to survive. He was right there. The last shells missed him. He watched them explode with indifference. When Peace came he was in Milan, billeted in the house of an innkeeper with a courtyard, flowers in tubs, little tables in the open, daughters making hats, and to Lucrezia, the younger daughter, he became engaged one evening when the panic was on him- that he could not feel".

6 "Bond Street fascinated her; Bond Street early in the morning in the season; its flags flying; its shops; no splash; no glitter; one roll of tweed in the shop where her father had bought his suits for fifth years; a few pearls; salmon on an iceblock".
} 
do trem, quando partiram de Newhaven; é bem possível que o próprio mundo não tenha sentido (WOOLF, 2012, p.97 e 98). ${ }^{7}$

Os teóricos com os quais dialogamos até aqui, que tratam dessas mudanças nas formas de percepção na modernidade (Berman, Giddens, Benjamin e Simmel), chamam sempre bastante atenção para o mundo que emergiu com os novos dispositivos de produção e reprodução de imagens, como a fotografia e o cinema. Mas não foram só as novas imagens que marcaram a vida moderna, os novos sons também invadiam essas cidades. Murray Schafer, em O Ouvido Pensante (1991), destaca as mudanças radicais pelas quais o ambiente sonoro passou nas culturas pós-industriais, caracterizadas por um congestionamento de sons. Se nas culturas primitivas $69 \%$ dos sons ao nosso redor eram naturais, na paisagem sonora ${ }^{8}$ das metrópoles modernas esses sons representam apenas $9 \%$ daquilo que escutamos, sendo 66\% da nossa escuta composta por sons de utensílios domésticos e da maquinaria industrial. (SCHAFER, 1991, p.128).

Apesar da introdução desses novos sons, a audição foi um dos sentidos mais enfraquecidos e atrofiados na modernidade. Marshall Mcluhan, em A Galáxia de Gutenberg (1972), afirma que a sociedade da imagem começa a se moldar com a invenção da tecnologia tipográfica, ainda no século XV, quando até as palavras se tornam parte do mundo visual. A invenção e a difusão da prensa móvel de Gutemberg, por volta de 1450, marca o fim da cultura oral nas civilizações europeias ocidentais, ou seja, "uma cisão entre a visão e a audição, entre o significado semântico e o código visual; e, portanto, somente a escrita fonética tem o poder de trasladar o homem da esfera tribal para a esfera civilizada, isto é, de substituir-lhe o ouvido pela vista." (MCLUHAN, 1972, p.44).

\footnotetext{
7 “'Beautiful! She would murmur, nudging Septimus, that he might see. But beauty was behind a pane of glass. Even taste (Rezia liked ices, chocolates, sweet things) had no relish to him. He put down his cup on the little marble table. He looked at people outside; happy they seemed, collecting in the middle of the street, shouting, laughing, squabbling over nothing. But he could not taste, he could not feel.(..). It might be possible, Septimus thought, looking at England from the train window, as they left Newhaven; it might be possible that the world itself is without meaning."
}

\footnotetext{
${ }^{8}$ A Paisagem Sonora é formada por diferentes sons que compõe um determinado ambiente, sejam esses sons de origem natural, humana, industrial ou tecnológica. Ver mais em Schafer (1991).
} 
Em Mrs. Dalloway, tanto a percepção visual quanto a sonora são fundamentais para a construção do fluxo de consciência. Clarissa, Septimus e os outros personagens da cidade estão sempre atentos aos sons das ruas de Londres, permeado pelas novas tecnologias, mas ainda preservando alguns fenômenos acústicos dos tempos antigos. Seja escutando a trepidação dos motores (WOOLF, 2012, p.16), ou o barulho dos aeroplanos que sobrevoam a cidade trazendo propagandas (Ibidem, p.22), seja na galeria de murmúrios das vozes que parecem formar um único som (Ibidem, p.20), a Sra. Dalloway surge como uma personagem atípica, já que parece não estar surda nem cega a essas minúcias da vida. O tempo cronológico do romance, por sinal, é marcado por um som que vira imagem nos pensamentos de Clarissa. Toda vez que a personagem escuta o barulho direto e inequívoco do Big Ben marcando as horas surge a expressão "círculos de chumbos se dissolvem no ar". 9 (Ibidem, p.54).

Além de romances e contos, Woolf deixou um enorme material com reflexões estéticas sobre literatura, tanto em forma de artigos publicados, como em notas presentes em seus diários. Nesses ensaios, um de seus temas prediletos era a busca pelo material adequado à literatura. Isso não quer dizer que a escritora tenha tentado impor um assunto que seria intrínseco aos textos literários. Pelo contrário, Woolf considerava que esses conteúdos eram variáveis dentro da história. É nesse sentido que a concepção da forma literária em Woolf se aproxima de Simmel e Benjamin, por exemplo, pois assim como a consciência é determinada historicamente pelo surgimento de novas técnicas, a literatura também o é. Dessa forma, os temas literários são transformados de época em época, acompanhando o bonde da história. A literatura de Woolf, portanto, refere-se a um homem afetado também fisiologicamente pelas mudanças técnicas ocorridas no mundo moderno.

No ensaio Mr. Bennett and Mrs. Brown (1924), Virginia Woolf argumenta sua posição contrária a corrente literária dominante, a tradição vitoriana que ela chama de materialista, pois esses escritores têm como preocupação maior as questões do corpo e não do espírito. $\mathrm{O}$ texto foi escrito em forma de resposta à afirmação de um referendado escritor inglês da época, Arnold Bennett, que declarou que a base da boa ficção era a criação de personagens que parecessem reais. Woolf então lança duas perguntas chaves: "O que é realidade? E quem são os juízes da realidade? Um personagem pode ser real para o Mr. Bennett e bastante irreal para

\footnotetext{
9 "the leaden circles dissolved in the air"
} 
mim". (WOOLF, 1924, p.10). Enquanto o personagem para Mr. Bennett era tudo o que poderia ser descrito sobre as suas características físicas, para geração de Woolf era tudo o que não poderia.

Diante das enormes mudanças vividas nesse período, a escritora declara ser impossível que a literatura se debruce sobre as mesmas questões e se utilize das mesmas formas dos escritores materialistas. Afirmando que "todas as relações humanas foram deslocadasaqueles entre senhores e servos, maridos e esposas, pais e filhos. E quando as relações humanas mudam há ao mesmo tempo uma mudança de religião, conduta, política e literatura.". (WOOLF, 1924, p.5).

Retornamos ao título deste trabalho: "novas formas para as nossas novas sensações" (WOOLF, 2011, p.9). Diante de todas essas mudanças no cotidiano, seria necessário criar artifícios que procurassem dar conta desse mundo de experiências audiovisuais singulares. A chamada literatura moderna parece surgir dessa necessidade. O caminho encontrado por Woolf, Joyce e Dorothy Richardson, por exemplo, foi justamente o fluxo de consciência, artifício que proporcionou um novo tratamento ao personagem do romance. A representação da consciência da forma mais verossímil possível, portanto, seria o novo material da ficção. Não seria a consciência de figuras históricas, nem a representação de grandes questões morais, mas a consciência do homem comum, que viu a transformação do mundo moderno diante dos seus olhos, olhando vitrines, andando de bonde, vendo filmes e sendo afetado pela publicidade.

Dessa forma, Woolf parece estar mais interessada naquilo que continua do que naquilo que começa, chega a um clímax, e termina. Esse foco no imediato e no desordenado fez com que a escritora incorporasse à literatura novas técnicas de apresentação do narrador e reformulasse antigos artifícios. A busca era por traduzir a essência do mecanismo do pensamento para aproximar-se ao máximo da vida.

\section{Referências Bibliográficas}

BANFIELD, Ann. Mrs. Dalloway in A cultura do Romance. São Paulo: Cosac Naify, 2009. 
BENJAMIN, Walter. O Narrador. In Obras Escolhidas. Magia e técnica, arte e política.São Paulo: editora Brasiliense, 1987.

Experiência e Pobreza. In Obras Escolhidas. Magia e técnica, arte e política. São Paulo: editora Brasiliense, 1987.

A Obra de Arte na Era da sua Reprodutibilidade Técnica. In Obras Escolhidas. Magia e técnica, arte e política. São Paulo: editora Brasiliense, 1987.

Sobre alguns temas em Baudelaire. In A modernidade e os modernos.

Rio de Janeiro: Tempo brasileiro, 2000.

BERMAN, Marshall. Tudo que é sólido desmancha no ar. São Paulo: Companhia das Letras, 1986.

GIDDENS, Anthony. Modernidade e Identidade. Rio de Janeiro: Zahar, 2002.

NATHAN, Monique. Virginia Woolf. Lisboa: Editora José Olympio, 1989.

O ouvido pensante. São Paulo: editora Unesp, 1991.

SIMMEL. A metrópole e a vida mental. In O fenômeno Urbano. Rio de Janeiro: Zahar editores, 1973.

WOOD, James. Como funciona a ficção. Trad. Denise Bottmann. São Paulo: Cosac Naify, 2011.

WOOLF, Virginia . Hours in Library in Virginia Woolf on Fiction. London: Hesperus Press Limited, 2011.

. Mrs. Dalloway. Tradução Tomaz Tadeu, Belo Horizonte: Autêntica, 2012. . Mrs. Dalloway. London: Martino Publishing, 2012.

. Modern Fiction. In: The Common Reader. Austrália: University of

Adelaide, 1919. Disponível em:

http://ebooks.adelaide.edu.au/w/woolf/virginia/w91c/chapter13.html\#chapter13. Acesso dia 05/08/2014.

Mr. Bennett and Mrs. Brown. London: The Hogarth Press, 1924.

eISSN: 2179-8478

DOI: $10.17851 / 2179-8478.8 .02-16$ 